\title{
The three year follow-up of the randomised "all-comers" trial of a biodegradable polymer biolimus-eluting stent versus permanent polymer sirolimus-eluting stent (LEADERS)
}

Joanna Wykrzykowska ${ }^{1}, \mathrm{MD}$, PhD; Patrick Serruys ${ }^{2 *}$, MD PhD; Pawel Buszman ${ }^{3}$, MD PhD; Axel Linke ${ }^{4}$, MD, $\mathrm{PhD}$; Thomas Ischinger ${ }^{5}, \mathrm{MD}, \mathrm{PhD}$; Volker Klauss ${ }^{6}, \mathrm{MD}, \mathrm{PhD}$; Franz Eberli ${ }^{7}, \mathrm{MD}, \mathrm{PhD}$; Roberto Corti ${ }^{7}, \mathrm{MD}^{2}$ $\mathrm{PhD}$; William Wijns ${ }^{8}, \mathrm{MD}$, PhD; Marie-Claude Morice ${ }^{9}, \mathrm{MD}, \mathrm{PhD}$; Carlo Di Mario ${ }^{10}$, MD, PhD; Robert-Jan Van Geuns $^{2}$, MD, PhD; Gerrit-Anne Van Es ${ }^{11}$, PhD; Peter Juni ${ }^{12}$, MD PhD; Stephan Windecker ${ }^{13}$, MD, PhD

\section{Academic Medical Center, Amsterdam, The Netherlands; 2. Thoraxcenter, Erasmus MC, Rotterdam, The Netherlands; 3. Medical University of Silesia, Katowicze, Poland; 4. Herzzentrum Leipzig, Leipzig, Germany; 5. Department of Cardiology, Hospital Bogenhausen, Munich, Germany; 6. Department of Cardiology, University Hospital Munich, Munich, Germany; 7. Department of Cardiology, University Hospital, Zurich, Switzerland; 8. Department of Cardiology, OLVZ, Aalst, Belgium; 9. Institut Cardiovasculaire, Paris-Sud, Massy, France; 10. Department of Cardiology, Royal Brompton Hospital, London, United Kingdom; 11. Cardialysis BV, Rotterdam, The Netherlands; 12. CTU Bern, Bern University Hospital, Bern, Switzerland; 13. Department of Cardiology, Bern University Hospital, Bern, Switzerland}

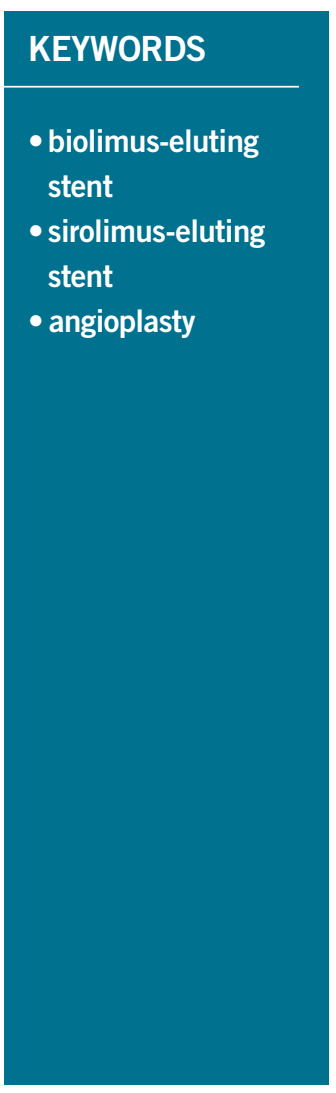

\section{Abstract}

Aims: The current study reports clinical outcomes at three year follow-up of the LEADERS clinical trial which was the first all-comers trial comparing a new generation biodegradable polymer biolimus drug-eluting stent (BES) with the first generation permanent polymer sirolimus-eluting stent (SES).

Methods and results: One thousand seven hundred and seven patients were randomised to unrestricted use of BES $(n=857)$ or SES $(n=850)$ in an all-comers population. Three year follow-up was available in $95 \%$ of the patients, 812 treated with BES and 809 treated with SES. At three years, BES remains non-inferior to SES for the primary endpoint of major adverse cardiac events (composite of cardiac death, myocardial infarction (MI), or clinically-indicated target vessel revascularisation (CI-TVR) (BES 15.7\% versus SES 19\%; HR 0.82 CI 0.65-1.03; $\mathrm{p}=0.09$ ). The MACE Kaplan Meier event curves increasingly diverge with the difference in events increasing from $1.4 \%$ to $2.4 \%$ and $3.3 \%$ at 1,2 and 3 years, respectively in favour of BES. The rate of cardiac death was non-significantly lower $4.2 \%$ versus $5.2 \%$ ( $\mathrm{HR}=0.81 \mathrm{CI} 0.52-1.26 ; \mathrm{p}=0.34$ ) and the rate of myocardial infarction was equivalent $7.2 \%$ versus $7.1 \%$ (HR 1.01 CI $0.70-1.44 ; \mathrm{p}=0.97$ ) for BES versus SES, respectively. Thus BES was non-inferior to SES in all the safety endpoints. Clinically-indicated TVR occurred in $9.4 \%$ of BES treated patients versus $11.1 \%$ of SES treated patients (HR 0.84 CI $0.62-1.13 ; \mathrm{p}=0.25$ ). Rates of definite stent thrombosis were $2.2 \%$ for BES and $2.9 \%$ for SES (HR 0.78 CI $0.43-1.43 ; \mathrm{p}=0.43$ ), with the event rate increase of $0.2 \%$ from one to three years for BES and $0.9 \%$ for SES. For patients presenting with ST-elevation myocardial infarction BES was superior to SES in reducing MACE.

Conclusions: The findings of the three year follow-up support the claim that the biodegradable polymer biolimuseluting stent has equivalent safety and efficacy to permanent polymer sirolimus-eluting stent in an all-comers patient population. Its performance is superior in some subpopulations such as in ST-elevation MI patients and event rates for BES are overall lower than for SES with a trend toward increasing divergence of outcomes over three years.

\footnotetext{
* Corresponding author: Thoraxcenter, Ba583a, Erasmus MC, 's-Gravendijkwal 230, 3015 CE Rotterdam, The Netherlands. E-mail:p.w.j.c.serruys@erasmusmc.nl
} 


\section{Introduction}

Drug-eluting stents (DES) dubbed the third revolution in interventional cardiology (after balloon angioplasty and bare metal stents being first and second) have to a large degree solved the problem of in-stent restenosis. ${ }^{1}$ However, the first generation devices such as sirolimus-eluting and paclitaxel-eluting stents with permanent polymer have relatively high rates of stent thrombosis, including very late stent thrombosis of up to $6 \%$ at five years in an all-comers unrestricted population (BernRotterdam). ${ }^{2}$ The reason for this high event rate is multifactorial but one of the prominent causes may be a hypersensitivity reaction and endothelial dysfunction caused by the permanent polymer from which the drug is eluted in the first generation DES. ${ }^{3,4}$

For this reason with the reduction of stent thrombosis in mind, Biomatrix Flex biolimus-eluting stent (BES) (Biosensors, Morges, Switzerland) was designed to elute biolimus from a polylactide (PLA) biodegradable polymer applied to the stent's abluminal surface. ${ }^{5}$ The polymer is fully metabolised to water and carbon dioxide within six to nine months from implantation leaving only the bare metal stainless steel platform behind. Biolimus is a semi-synthetic highly lipophilic inhibitor of the mammalian target of rapamycin, ten times as potent as sirolimus. BES has been shown to be noninferior to the sirolimus-eluting permanent polymer stent at 9 and 12 months in terms of major adverse cardiac events in the all-comers LEADERS clinical trial. ${ }^{6}$ The current study is a report of three year outcomes of the first all-comers trial in an unrestricted population of BES versus SES with focus on special patient populations and very late definite stent thrombosis risk, especially in patients who have interrupted DAPT therapy.

\section{Methods}

\section{STUDY POPULATION}

LEADERS was a multicentre European non-inferiority trial comparing the safety and efficacy of the BioMatrix ${ }^{\mathrm{TM}}$ Flex biolimuseluting stent with a biodegradable polymer (BES) (Biosensors, Morges, Switzerland) to the Cypher ${ }^{\circledast}$ SelectTM sirolimus-eluting stent with a durable polymer (SES) (Cordis, Warren, NJ, USA) in 1,707 "all-comers" patients. The detailed study protocol can be found in the main publication. ${ }^{6}$ Briefly, patients included had chronic stable coronary artery disease or acute coronary syndromes including ST-elevation myocardial infarction, one of more lesions of $>50 \%$ and a reference vessel diameter $2.25-3.5 \mathrm{~mm}$. The only exclusion criteria were: known allergy to acetylsalicylic acid, clopidogrel, heparin, stainless steel, sirolimus, biolimus or contrast that cannot be pre-medicated, planned surgery within six months of PCI unless DAPT could be continued through surgery, pregnancy or participation in another trial before reaching its primary endpoint. The study complied with the Declaration of Helsinki and was approved by all institutional ethics committees. All patients provided written, informed consent for participation in the trial.

\section{RANDOMISATION AND PROCEDURES}

Randomisation was performed centrally after diagnostic cardiac catheterisation and before percutaneous coronary intervention
(PCI) by use of a telephone allocation service (Limburgia Telefonische Antwoord Service BV, Rotterdam, The Netherlands). The allocation sequence was computer generated, stratified according to centre, and blocked with block sizes of 8 and 16, which varied randomly. We randomly allocated patients on a1:1 basis to treatment with a BES or a SES and to active angiographic follow-up at nine months or clinical follow-up only on a 1:3 basis, with a factorial design.

BES were available in diameters of $2.25-3.5 \mathrm{~mm}$ and in lengths of 8-28 mm. SES were available in diameters of 2.25$3.5 \mathrm{~mm}$ and in lengths of $8-33 \mathrm{~mm}$. We performed balloon angioplasty and stent implantation according to standard technique and direct stenting was allowed. No mixture of drug-eluting stents was permitted within a given patient, unless the operator was unable to insert the study stent, in which case crossover to another device of the operator's choice was possible. Before or at the time of the procedure, patients were given at least $75 \mathrm{mg}$ of acetylsalicylic acid, 300-600 mg loading dose of clopidogrel, and unfractionated heparin at a dose of at least 5,000 I or $70-100 \mathrm{IU} / \mathrm{kg}$. After the procedure, all patients were advised to take aspirin indefinitely and clopidogrel for at least 12 months. In case of intercurrent revascularisation procedures requiring stent implantation, treating cardiologists were encouraged to use the study stent. For other details we refer to the primary endpoint publication. ${ }^{6}$

\section{STUDY ENDPOINTS}

Definitions of all endpoints are provided elsewhere. ${ }^{6}$ The primary endpoint of this sub-study was MACE, defined as the composite of cardiac death, MI, and clinically-indicated target vessel revascularisation (TVR) within 9-months. Secondary endpoints were any target lesion revascularisation (TLR) (both clinically and non-clinically indicated), any TVR, cardiac death, death from any cause, myocardial infarction, stent thrombosis (defined according to the Academic Research Council) ${ }^{7,8}$, device success, and lesion success.

\section{STATISTICS}

The trial was powered for non-inferiority on the primary clinical endpoint. Continuous variables are expressed as mean+standard deviation and compared with student $t$-test. Categorical variables are presented as frequency (percentages) and compared using chisquare test. Survival curves were constructed using Kaplan-Meier estimates, and compared by the log-rank test. The Mantel-Cox model was used for the rate ratios of clinical outcome. All analyses were performed using SAS 8.02 (SAS Institute Inc, Cary, NC, USA) by a dedicated statistician. All p-values and confidence intervals were two-sided and $\mathrm{p}<0.05$ was considered significant.

\section{Results}

\section{FOLLOW-UP RATE AT THREE YEARS}

Figure 1 flow chart summarises the follow-up rates at 1,2 and 3 years. Follow-up was available in 1,621 patients i.e., 95\%. In the BES treated group 17 patients were lost to follow-up whereas 20 


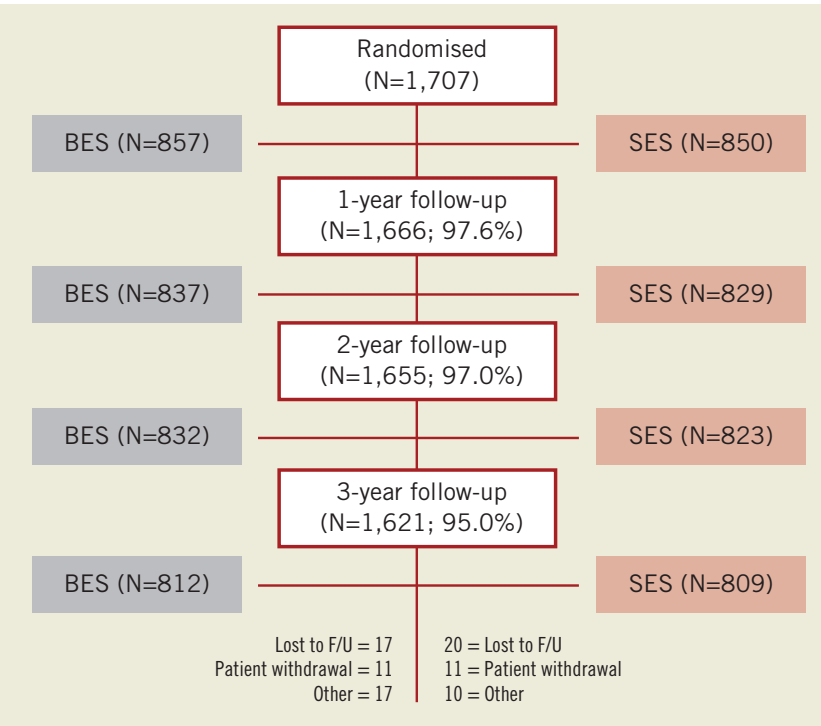

Figure 1. Flow chart showing completeness of follow-up at 1, 2 and 3 years.

A. MACE

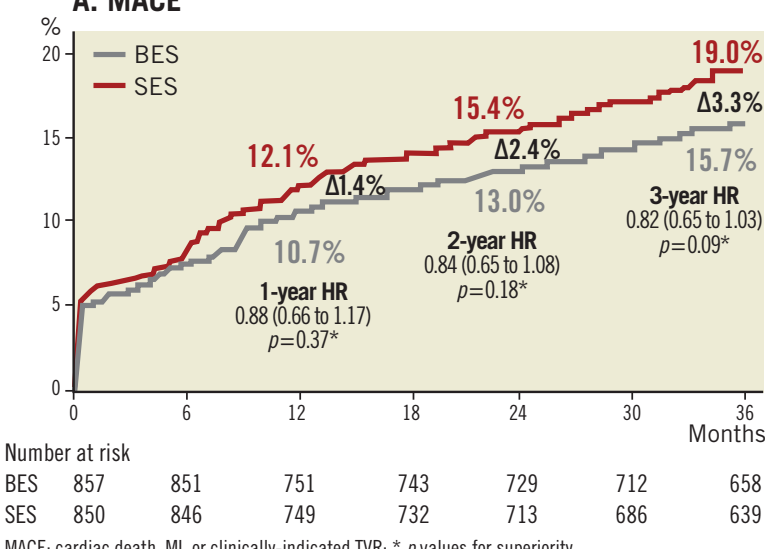

MACE: cardiac death, MI, or clinically-indicated TVR; * $p$ values for superiority were lost to follow-up in the SES treated group. Eleven patients in each treatment arm withdrew consent.

\section{PATIENT DEMOGRAPHICS AND LESION CHARACTERISTICS}

The baseline clinical and angiographic characteristics are summarised in Table 1, respectively. There were no significant differences between the two stent groups.

\section{CLINICAL OUTCOMES AT 36 MONTHS (THREE YEARS)}

At three years BES remained non-inferior to SES for the primary endpoint of major adverse cardiac events (composite of cardiac death, myocardial infarction (MI), or clinically-indicated target vessel revascularisation (TVR)) (BES 15.7\% versus SES 19\%; HR 0.82 CI 0.65-1.03; $p=0.09$ ). The MACE Kaplan Meier event curves tend to increasingly diverge with the difference in events increasing from $1.4 \%$ to $2.4 \%$ and $3.3 \%$ at 1,2 and 3 years, respectively in favour of BES (Figure 2A). The rate of cardiac death was non-significantly lower $4.2 \%$ versus $5.2 \%(\mathrm{HR}=0.81 \mathrm{CI} 0.52-1.26$; $\mathrm{p}=0.34$; Figure 2B) and the rate of myocardial infarction was equivalent $7.2 \%$ versus $7.1 \%$ (HR 1.01 CI $0.70-1.44 ; p=0.97$; Figure 2 C) for
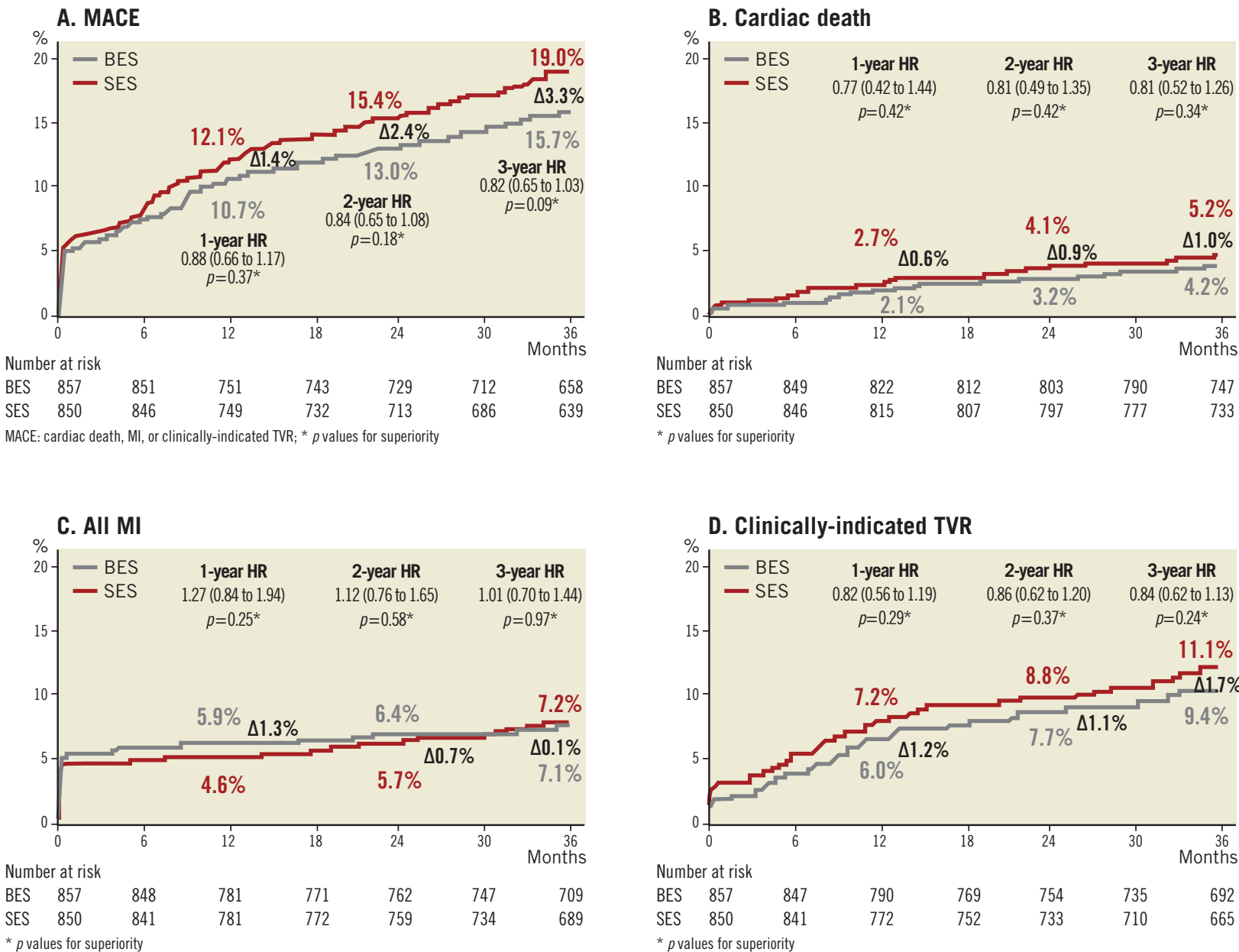

D. Clinically-indicated TVR

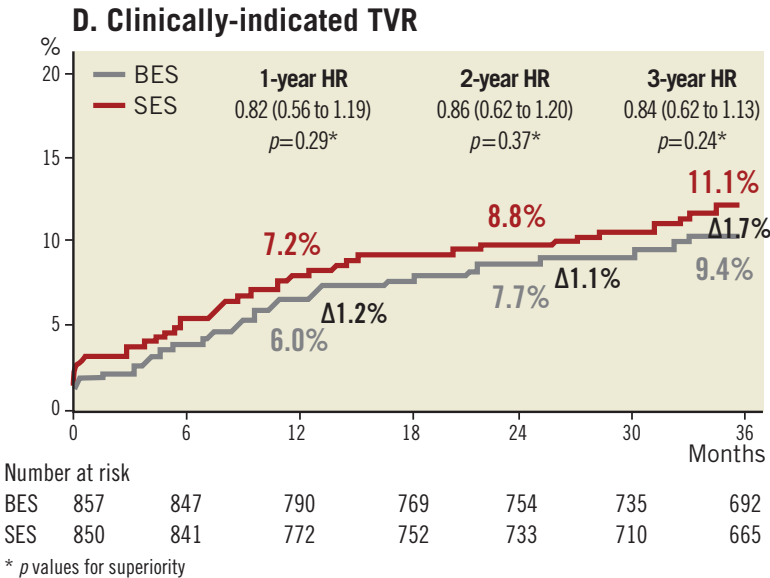

Figure 2. A. Kaplan Meier curve for MACE (cardiac death, myocardial infarction and target vessel revascularisation) rate at three years and Hazard ratios for superiority: BES (grey) versus SES (red). B. Kaplan Meier curve for cardiac death at three years. C. Kaplan Meier curve for all myocardial infarctions at three years. D. Kaplan Meier curve for target vessel revascularisation at three years. 
Table 1. Baseline demographic and angiographic patient data.

\begin{tabular}{|c|c|c|}
\hline \multicolumn{3}{|c|}{ Patient demographics } \\
\hline & $\begin{array}{c}\text { BES } \\
857 \text { patients }\end{array}$ & $\begin{array}{c}\text { SES } \\
\mathbf{8 5 0} \text { patients }\end{array}$ \\
\hline Age in years & $65 \pm 11$ & $65 \pm 11$ \\
\hline Male gender & $75 \%$ & $75 \%$ \\
\hline Arterial hypertension & $74 \%$ & $73 \%$ \\
\hline Diabetes mellitus & $26 \%$ & $23 \%$ \\
\hline insulin-dependent & $10 \%$ & $9 \%$ \\
\hline Hypercholesterolaemia & $65 \%$ & $68 \%$ \\
\hline Family history & $40 \%$ & $44 \%$ \\
\hline Smoking & $24 \%$ & $25 \%$ \\
\hline Previous MI & $32 \%$ & $33 \%$ \\
\hline Previous PCl & $36 \%$ & $37 \%$ \\
\hline with drug-eluting & $12 \%$ & $14 \%$ \\
\hline Previous CABG & $11 \%$ & $13 \%$ \\
\hline Chronic stable angina & $45 \%$ & $44 \%$ \\
\hline \multicolumn{3}{|c|}{ Patient characteristics } \\
\hline Acute coronary syndrome & $55 \%$ & $56 \%$ \\
\hline$\%$ Unstable angina & $22 \%$ & $21 \%$ \\
\hline$\%$ Non-ST-elevation & $17 \%$ & $18 \%$ \\
\hline \% ST-S evation MI & $16 \%$ & $17 \%$ \\
\hline Left ventricular ejection traction & $56 \pm 11 \%$ & $55 \pm 12 \%$ \\
\hline Number of lesions per patient & $1.5 \pm 0.7$ & $1.4 \pm 0.7$ \\
\hline \multicolumn{3}{|l|}{ Lesions per patient } \\
\hline$\% 1$ lesion & $63 \%$ & $69 \%$ \\
\hline$\% 2$ lesions & $29 \%$ & $22 \%$ \\
\hline$\% 3$ lesions & $7 \%$ & $8 \%$ \\
\hline$\%>4$ lesions & $1 \%$ & $2 \%$ \\
\hline De novo lesions & $92 \%$ & $91 \%$ \\
\hline Long lesions (>20 mm) & $31 \%$ & $27 \%$ \\
\hline Small vessels (RVD <2.75 mm) & $68 \%$ & $67 \%$ \\
\hline Off label use & $81 \%$ & $78 \%$ \\
\hline
\end{tabular}

BES versus SES, respectively. Thus BES was non-inferior to SES in all the safety endpoints at three years (Figure 3A). Clinicallyindicated TVR occurred in $9.4 \%$ of BES treated patients versus $11.1 \%$ of SES treated patients (HR 0.84 CI 0.62-1.13; $\mathrm{p}=0.25$; Figure 2D). BES was non-inferior to SES in efficacy endpoints at three years (Figure 3B).

\section{SUBPOPULATIONS (PRE-SPECIFIED AND POST HOC)}

The findings of the primary endpoint (MACE) were consistent across the pre-specified analyses for diabetes, acute coronary syndromes, de novo lesions, left anterior descending lesions, off-label use, small vessels and long-lesions except a significant interaction was observed between estimated HR and presence or absence of ST-elevation myocardial infarction at baseline (HR 0.43; CI 0.22-0.83; p=0.01) (Figure 4). In addition, there was a trend to reduction in event rates with the use of BES in patients with multivessel disease (HR 0.65; CI 0.411.03; $\mathrm{p}=0.06$ ). Post hoc analysis of the highest SYNTAX score tertile patients (defined as SYNTAX score $>16$ ) showed significantly lower cardiac death for patients treated with BES (4.7\% versus $10.5 \%$; HR 0.43; CI 0.21-0.89; $\mathrm{p}=0.02$ ) (Figure 5).

\section{STENT THROMBOSIS AND DAPT TREATMENT}

Rates of definite stent thrombosis were $2.2 \%$ for BES and $2.9 \%$ for SES (HR 0.78 CI 0.43-1.43; p=0.43), with the event rate increase of $0.2 \%$ from one to three years for BES and $0.9 \%$ for SES (Figure 6). Table 2 summarises the rates of antiplatelet agent utilisation at 9, 12, 24 and 36 months which were not different in the BES and SES group (aspirin use of $94 \%$ and clopidogrel use of $20 \%$ ). Among patients who discontinued DAPT before 12 months, definite stent thrombosis occurred in four patients treated with SES and none treated with BES. Among patients who discontinued clopidogrel after 12 months, definite stent thrombosis occurred in two patients treated with SES and none treated with BES (Figure 7).

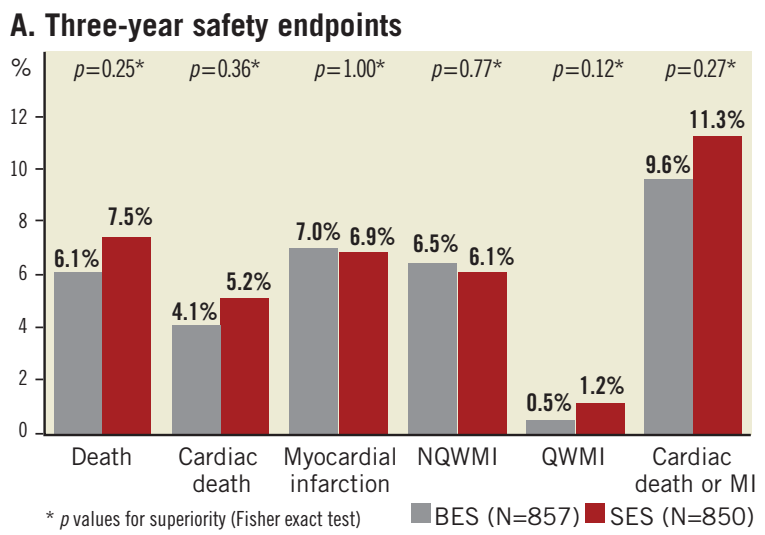

\section{B. Three-year efficacy endpoints}

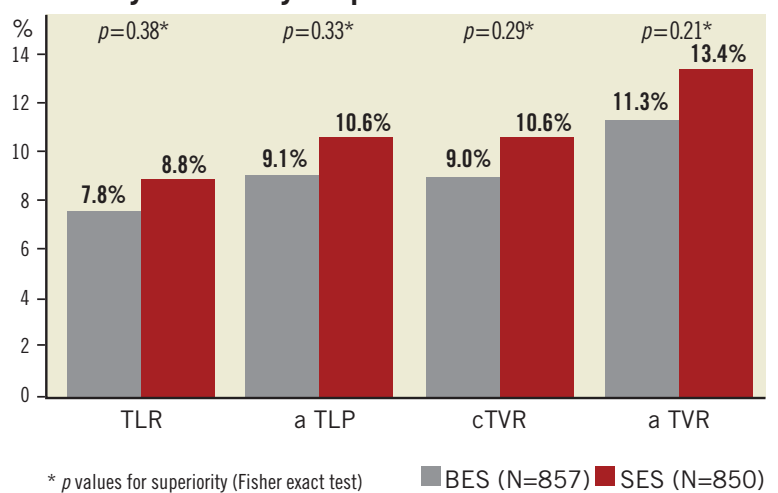




\begin{tabular}{|c|c|c|c|c|c|}
\hline & BES & SES & Risk ratio (95\% Cl) & $p$ value & $p_{\text {test }}$ \\
\hline Overall & $132 / 857$ & $157 / 850$ & 0.80 (0.63 to 1.03 ) & & ns \\
\hline Diabetes mellitus & & & & & ns \\
\hline Yes & $53 / 223$ & $45 / 191$ & 1.02 (0.68 to 1.52 ) & 0.92 & \\
\hline No & $79 / 634$ & $112 / 659$ & 0.72 (0.54 to 0.96) & 0.02 & \\
\hline Acute coronary & & & & & ns \\
\hline Yes & $68 / 470$ & $87 / 473$ & 0.77 (0.56 to 1.06$)$ & 0.11 & \\
\hline No & $64 / 387$ & 70/377 & 0.88 (0.63 to 1.25$)$ & 0.48 & \\
\hline ST-elevation MI & & & & & 0.03 \\
\hline Yes & $13 / 135$ & $29 / 140$ & 0.43 (0.22 to 0.83$)$ & 0.01 & \\
\hline No & $119 / 722$ & $128 / 710$ & 0.91 (0.71 to 1.18) & 0.48 & \\
\hline Left anterior & & & & & ns \\
\hline Yes & $59 / 407$ & $71 / 417$ & 0.84 (0.59 to 1.17 ) & 0.32 & \\
\hline No & $73 / 449$ & $86 / 431$ & 0.81 (0.59 to 1.11$)$ & 0.18 & \\
\hline Multivessel disease & & & & & ns \\
\hline Yes & $33 / 209$ & $42 / 176$ & 0.65 (0.41 to 1.03$)$ & 0.06 & \\
\hline No & $99 / 643$ & $115 / 674$ & 0.89 (0.68 to 1.16$)$ & 0.39 & \\
\hline Off-label use & & & & & ns \\
\hline Yes & $116 / 696$ & $135 / 665$ & 0.81 (0.63 to 1.04$)$ & 0.09 & \\
\hline No & $16 / 160$ & $22 / 183$ & 0.83 (0.44 to 1.59 ) & 0.58 & \\
\hline De novolesions & & & & & ns \\
\hline Yes & $114 / 788$ & $136 / 774$ & 0.82 (0.64 to 1.05$)$ & 0.11 & \\
\hline No & $18 / 68$ & $21 / 74$ & 0.92 (0.49 to 1.73 ) & 0.79 & \\
\hline Small-vessel disease & & & & & ns \\
\hline Yes & $96 / 535$ & $104 / 568$ & $0.89(0.68$ to 1.18$)$ & 0.43 & \\
\hline No & $36 / 271$ & $53 / 280$ & $0.68(0.45$ to 1.04$)$ & 0.08 & \\
\hline Long lesions & & & & & ns \\
\hline Yes & $46 / 262$ & $52 / 225$ & $0.74(0.50$ to 1.10$)$ & 0.14 & \\
\hline No & $86 / 594$ & $105 / 623$ & 0.85 (0.64 to 1.13$)$ & 0.27 & \\
\hline
\end{tabular}

Figure 4. MACE rate for patients treated with BES versus SES stratified by pre-specified subgroups: diabetic patients, acute coronary syndrome at presentation, ST-elevation myocardial infarction at presentation, left anterior descending artery disease, multivessel disease, off-label use, de novo lesions, small vessels and long lesions. BES performs superiorly to DES in patients presenting with ST-elevation myocardial infarction.

\section{Cardiac death for SYNTAX $>16$}

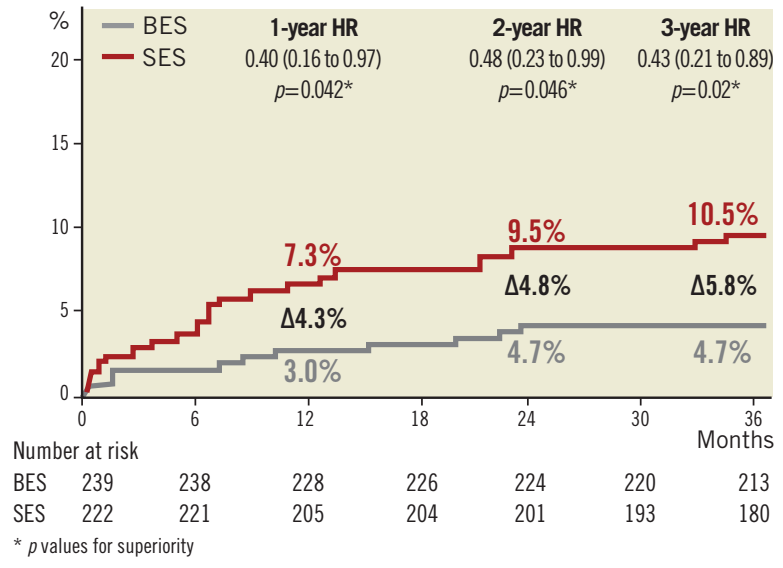

Figure 5. Cardiac death for patients in the highest tertile of the SYNTAX score is lower for patients treated with BES versus SES at three years (HR 0.43; $p=0.02$ ).
Define stent thrombosis

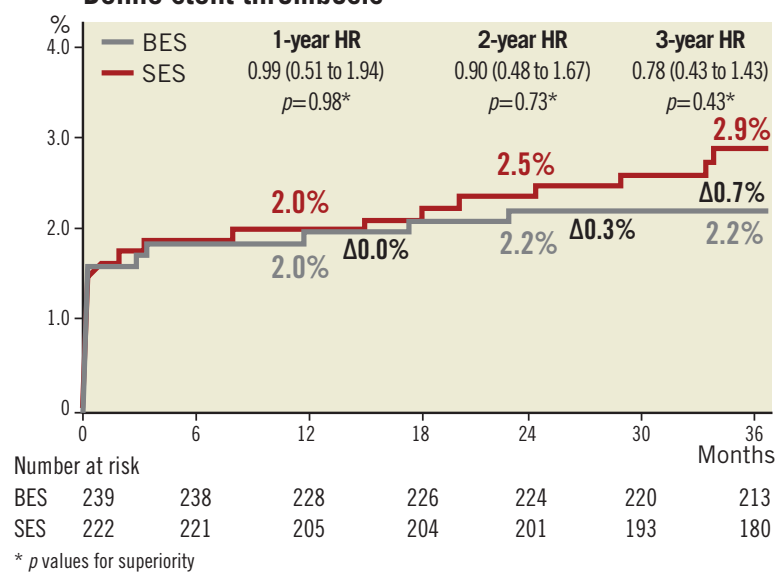

Figure 6. Definite stent thrombosis rate at three years for patients treated with BES versus SES showing greater increases in very late events for SES. 
Table 2. Antiplatelet agent utilisation at 9, 12, 24 and 36 months for patients treated with BES and SES.

\begin{tabular}{|c|c|c|c|}
\hline & BES & SES & $p$ value \\
\hline \multicolumn{4}{|l|}{ Aspirin } \\
\hline At 9 months & $96.6 \%(n=818)$ & $97.4 \%(n=798)$ & 0.39 \\
\hline At 12 months & $97.0 \%(n=810)$ & $96.1 \%(n=801)$ & 0.34 \\
\hline At 24 months & $94.9 \%(n=789)$ & $94.2 \%(n=778)$ & 0.58 \\
\hline At 36 months & $94.3 \%(n=757)$ & $94.8 \%(n=745)$ & 0.73 \\
\hline \multicolumn{4}{|c|}{ Clopidrogel/Thienopyridine } \\
\hline At 9 months & $95.6 \%(n=818)$ & $95.2 \%(n=798)$ & 0.81 \\
\hline At 12 months & $68.1 \%(n=810)$ & $56.5 \%(n=801)$ & 0.52 \\
\hline At 24 months & $23.4 \%(n=789)$ & $24.3 \%(n=778)$ & 0.72 \\
\hline At 36 months & $19.6 \%(n=757)$ & $20.4 \%(n=747)$ & 0.75 \\
\hline
\end{tabular}

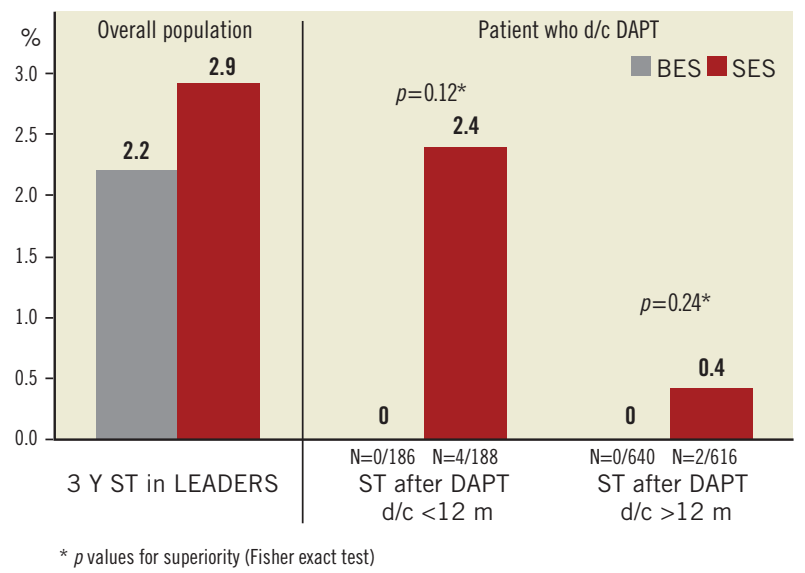

Figure 7. The effect of DAPT discontinuation before 12 months and after 12 months post-procedure on stent thrombosis events in patients treated with BES (no events) versus SES.

\section{Discussion}

This study confirms that biodegradable polymer biolimus-eluting stent (BES) is non-inferior to the permanent polymer sirolimuseluting stent (SES) at three year follow-up in the context of an unrestricted use in a randomised "all-comers" trial. The primary clinical endpoint of MACE (combined cardiac death, myocardial infarction and clinically indicated target vessel revascularisation) continues to show a lower event rate for patients treated with BES with incremental benefit to the use of BES over SES and with a trend towards statistical significance. In addition, the subgroup analysis confirms that high-risk patients such as patients presenting with acute STelevation myocardial infarction have better outcomes with BES treatment. Patients with a high SYNTAX score have a lower cardiac death rate when treated with BES when compared to SES. ${ }^{9}$

The major strength of this trial is that it tested the performance of the new generation biodegradable polymer drug-eluting stent in a patient population that has close to an $80 \%$ off-label use as well as an increased risk of adverse events. It reflects the real clinical practice and therefore tests the device in the real-world setting. ${ }^{10}$ Thus in both treatment groups the event rates are overall higher than the ones reported from the initial DES trials and some of the more recent randomised trials such as ENDEAVOR IV and SPIRIT III in which simple de novo lesions were treated. ${ }^{11-14}$ In addition, while ENDEAVOR and SPIRIT used angiographically-driven outcomes (lesion-based and device-based analysis), LEADERS focused on patient-based clinical outcomes: all cardiac death, all MI and all clinically-driven TVR.

The use of the first generation drug-eluting stents has been associated with an increased risk of stent thrombosis, an issue that was of particular importance in off-label indication cases. ${ }^{15}$ We show in this study that the biodegradable polymer BES has lower stent thrombosis rates than the permanent polymer stent of the first generation. The differences do not reach statistical significance as the trial has not been powered to detect them, and registry data with larger patient numbers or longer follow-up will be needed to confirm whether biodegradable polymer DES can reduce stent thrombosis rates. The Bern-Rotterdam registry shows that event rates steadily increase for sirolimus-eluting stents at $0.6 \%$ per year. ${ }^{2,16}$ Similarly in ARTS-II overall stent thrombosis rate reaches $9.4 \%$ at five years for sirolimus stent treated patients. ${ }^{17}$ If the average very late definite stent thrombosis rate is $0.1 \%$ for BES and $0.6 \%$ for SES, one can project that the differences in stent thrombosis for $B E S$ versus SES may reach statistical significance. OCT analysis at nine months seems to suggest that biodegradable polymer biolimus-eluting stent has better strut coverage than the permanent polymer sirolimus-eluting stent. ${ }^{18}$ In addition, patients who stopped DAPT do not appear to have any additional events at three years in the BES arm while these events do accrue in the SES arm.

\section{Limitations}

The study was performed in a tertiary care centre with high volume operators throughout Europe and thus the results might not be generalisable to low volume peripheral centres.

\section{Conclusions}

The findings of the three year follow-up support the claim that biodegradable polymer biolimus-eluting stent has equivalent safety and efficacy to permanent polymer sirolimus-eluting stent in an all-comers patient population. Its performance is superior in some subpopulations such as ST-elevation MI patients and event rates for BES are overall lower than for SES with increasing divergence of Kaplan Meier curves.

\section{Conflict of interest statement}

The authors have no conflict of interest to declare.

\section{References}

1. Wykrzykowska JJ, Onuma Y, Serruys PW. Advances in stent drug delivery: the future is in bioabsorbable stents. Expert Opin Drug Deliv. 2009;6:113-126.

2. Daemen J, Wenaweser P, Tsuchida K, Abrecht L, Vaina S, Morger C, Kukreja N, Juni P, Sianos G, Hellige G, van Domburg RT, 
Hess OM, Boersma E, Meier B, Windecker S, Serruys PW. Early and late coronary stent thrombosis of sirolimus-eluting and paclitaxel-eluting stents in routine clinical practice: data from a large two-institutional cohort study. Lancet. 2007;369:667-678.

3. Cook S, Ladich E, Nakazawa G, Eshtehardi P, Neidhart M, Vogel R, Togni M, Wenaweser P, Billinger M, Seiler C, Gay S, Meier B, Pichler WJ, Juni P, Virmani R, Windecker S. Correlation of intravascular ultrasound findings with histopathological analysis of thrombus aspirates in patients with very late drug-eluting stent thrombosis. Circulation. 2009;120:391-399.

4. van der Giessen WJ, LincoffAM, Schwartz RS, van Beusekom HM, Serruys PW, Holmes DR, Jr., Ellis SG, Topol EJ. Marked inflammatory sequelae to implantation of biodegradable and nonbiodegradable polymers in porcine coronary arteries. Circulation. 1996;94:1690-1697.

5. Grube E, Buellesfeld L. BioMatrix Biolimus A9-eluting coronary stent: a next-generation drug-eluting stent for coronary artery disease. Expert Rev Med Devices. 2006;3:731-741.

6. Windecker S, Serruys PW, Wandel S, Buszman P, Trznadel S, Linke A, Lenk K, Ischinger T, Klauss V, Eberli F, Corti R, Wijns W, Morice MC, di Mario C, Davies S, van Geuns RJ, Eerdmans P, van Es GA, Meier B, Juni P. Biolimus-eluting stent with biodegradable polymer versus sirolimus-eluting stent with durable polymer for coronary revascularisation (LEADERS): a randomised non-inferiority trial. Lancet. 2008;372:1163-1173.

7. Mauri L, Hsieh WH, Massaro JM, Ho KK, D'Agostino R, Cutlip DE. Stent thrombosis in randomized clinical trials of drug-eluting stents. N Engl J Med. 2007;356:1020-1029.

8. Vranckx P, Kint PP, Morel MA, Van Es GA, Serruys PW, Cutlip DE. Identifying stent thrombosis, a critical appraisal of the academic research consortium (ARC) consensus definitions: a lighthouse and as a toe in the water. EuroIntervention. 2008;4 Suppl C:C39-44.

9. Wykrzykowska JJ, Garg S, Girasis C, de Vries T, Morel MA, van Es GA, Buszman P, Linke A, Ischinger T, Klauss V, Corti R, Eberli F, Wijns W, Morice MC, di Mario C, van Geuns RJ, Juni P, Windecker S, Serruys PW. Value of the SYNTAX score for risk assessment in the all-comers population of the randomized multicenter LEADERS (Limus Eluted from A Durable versus ERodable Stent coating) trial. J Am Coll Cardiol. 2010;56:272-277.

10. Beohar N, Davidson CJ, Kip KE, Goodreau L, Vlachos HA, Meyers SN, Benzuly KH, Flaherty JD, Ricciardi MJ, Bennett CL, Williams DO. Outcomes and complications associated with off-label and untested use of drug-eluting stents. JAMA. 2007;297:1992-2000.

11. Kirtane AJ, Gupta A, Iyengar S, Moses JW, Leon MB, Applegate R, Brodie B, Hannan E, Harjai K, Jensen LO, Park SJ, Perry R, Racz M, Saia F, Tu JV, Waksman R, Lansky AJ, Mehran R,
Stone GW. Safety and efficacy of drug-eluting and bare metal stents: comprehensive meta-analysis of randomized trials and observational studies. Circulation. 2009;119:3198-3206.

12. Morice MC, Serruys PW, Sousa JE, Fajadet J, Ban Hayashi E, Perin M, Colombo A, Schuler G, Barragan P, Guagliumi G, Molnar F, Falotico R. A randomized comparison of a sirolimus-eluting stent with a standard stent for coronary revascularization. $N$ Engl J Med. 2002;346:1773-1780.

13. Leon MB, Mauri L, Popma JJ, Cutlip DE, Nikolsky E, O'Shaughnessy C, Overlie PA, McLaurin BT, Solomon SL, Douglas JS, Jr., Ball MW, Caputo RP, Jain A, Tolleson TR, Reen BM, 3rd, Kirtane AJ, Fitzgerald PJ, Thompson K, Kandzari DE. A randomized comparison of the ENDEAVOR zotarolimus-eluting stent versus the TAXUS paclitaxel-eluting stent in de novo native coronary lesions 12-month outcomes from the ENDEAVOR IV trial. $J$ Am Coll Cardiol. 2010;55:543-554.

14. Stone GW, Midei M, Newman W, Sanz M, Hermiller JB, Williams J, Farhat N, Caputo R, Xenopoulos N, Applegate R, Gordon P, White RM, Sudhir K, Cutlip DE, Petersen JL. Randomized comparison of everolimus-eluting and paclitaxel-eluting stents: two-year clinical follow-up from the Clinical Evaluation of the Xience V Everolimus Eluting Coronary Stent System in the Treatment of Patients with de novo Native Coronary Artery Lesions (SPIRIT) III trial. Circulation. 2009;119:680-686.

15. Win HK, Caldera AE, Maresh K, Lopez J, Rihal CS, Parikh MA, Granada JF, Marulkar S, Nassif D, Cohen DJ, Kleiman NS. Clinical outcomes and stent thrombosis following off-label use of drugeluting stents. JAMA. 2007;297:2001-2009.

16. Wenaweser P, Daemen J, Zwahlen M, van Domburg R, Juni P, Vaina S, Hellige G, Tsuchida K, Morger C, Boersma E, Kukreja N, Meier B, Serruys PW, Windecker S. Incidence and correlates of drug-eluting stent thrombosis in routine clinical practice. 4-year results from a large 2-institutional cohort study. J Am Coll Cardiol. 2008;52:1134-1140.

17. Serruys PW, Onuma Y, Garg S, Vranckx P, De Bruyne B, Morice MC, Colombo A, Macaya C, Richardt G, Fajadet J, Hamm C, Schuijer M, Rademaker T, Wittebols K, Stoll HP. 5-year clinical outcomes of the ARTS II (Arterial Revascularization Therapies Study II) of the sirolimus-eluting stent in the treatment of patients with multivessel de novo coronary artery lesions. $\mathrm{J} \mathrm{Am}$ Coll Cardiol. 2010;55:1093-1101.

18. Barlis P, Regar E, Serruys PW, Dimopoulos K, van der Giessen WJ, van Geuns RJ, Ferrante G, Wandel S, Windecker S, van Es GA, Eerdmans P, Juni P, di Mario C. An optical coherence tomography study of a biodegradable vs. durable polymer-coated limus-eluting stent: a LEADERS trial sub-study. Eur Heart J. 2010;31:165-176. 